\title{
STRENGTH ANALYSIS WITH WIND INFLUENCE ON A HYBRID MULTIMEDIA MOBILE SCENE
}

\author{
Liss M.*, Kalaczyński T.**, Dluhunovych N.***
}

\begin{abstract}
The mobile scene subjected to strength analysis is an extraordinary temporary building, whose endurance in relation to very high variability and diversity of operating conditions is the main theme of this study. The paper also presents the issue of analyzing this type of structure in design offices and in the light of applicable standards. Selected results of strength analysis carried out in CAD/CAE software were also presented.
\end{abstract}

Keywords: Finite element method, Mobile scene construction, Stress analysis, Wind influence.

\section{Introduction}

Mobile scenes are mainly steel or steel-aluminum constructions capable of traveling over very large distances, sometimes even in thousands of kilometers. This particular feature of the scene construction associated with their mobility that causes significant dynamic loads in addition to static loads. However, designers are usually limited to analyzing constructions for static loads, specifying dynamic loads as low and negligible. This approach can negatively affect its endurance. Therefore, at least for the newly designed and already existing constructions of mobile scenes should be used measurement methods based on modal analysis, that are already effectively used in relation to other technical objects (Łukasiewicz, 2014). This approach would allow continuous monitoring of the technical condition of the construction, thus reducing the probability of a threat to safety of use. The complex nature of loads affecting the construction of mobile scenes occurs both in the case of the complex scene and the unfolded scene. This form of operational loads also affecting into construction fatigue strength (Ligaj, 2016 and Strzelecki, 2019), leading to tragic disasters in some situations (Kinasz, 2007 and Supel, 2014). One of the main causes of steel construction catastrophies are most often considered errors made on during design (Kinasz, 2007), when regarding loads, materials and other construtional features are established. These errors can result not only from insufficient experience or qualifications, but also from the limitations of the tools used in design offices to conduct strength analysis. The positive side of this type of situation is the ability to draw conclusions that contribute to the modernization of existing solutions, for example: nowadays, commonly carried out in design offices, strength analyzes on 2D models are displaced by analyzes on 3D models (Błyskal, 2015), which reflect real conditions much more in which the structure will be used. The construction of the mobile scene in an unfolded state in accordance with Polish building law is treated as a temporary construction, which can be subjected to the same types of loads as in the case of other typical buildings. The unusual nature of the construction of mobile scenes in the light of scientific considerations is mainly demonstrated by the very large variability and variety of conditions in which it can be exploited. Nowadays, it is observed that rivalry of producers of mobile scene constructions has passed to the ground of directives, regulations and norms. Especially often citing the so-called Eurocode standards, which among other things contain arrangements for wind loads. It is interesting that Eurocode standards are dedicated to building and engineering objects whose mainly characterize of stationary which is a kind of invariance in the context of location (PN-EN 1991-1-4, 2008). The diversity of interpretations of the information contained in the norms regarding the

\footnotetext{
Assoc. Prof. Michał Liss, PhD.: Institute of Machine Exploatation and Transport, University of Science and Technology, Al. prof. S. Kaliskiego 7; 85-796, Bydgoszcz; PL, michal.liss@utp.edu.pl

** Assoc. Prof. Tomasz Kałaczyński, PhD.: Institute of Machine Exploatation and Transport, University of Science and Technology, Al. prof. S. Kaliskiego 7; 85-796, Bydgoszcz; PL, tomasz.kalaczynski@utp.edu.pl

*** Assoc. Prof. Natalia Dluhunovych, PhD.: Faculty of Programming Computer and Telecommunication System, Khmelnytsky National University; Instytuts'ka 11; 29016, Khmelnytsky; UKR, dlugunovich@gmail.com
} 
influence of wind on building constructions has contributed to the creation of many books (Kozłowski, 2015 and Lipecki, 2015) and scientific publications (Lipecki, 2013 and Żurański, 2010). The authors indicate in them a number of important parameters such as: wind speed, direction, terrain and nearby environment, which significantly affect the load characteristics of the building. The correct interpretation of the content of the norms is extremely important, taking into account that the mobile scenes constructions are most often the main point of mass events. Therefore, the best case for analyzing the strength of a mobile scene construction is a variant that will take the most difficult and complex load conditions. Determining locations about such conditions is not a problem if we limited to one country, which in the case of large mobile scenes is practically impossible. Another problematic area is how to classify a mobile scene construction as kind of building. If the mobile scene is roofed only from above and all other walls are exposed, you can treat this structure as a carport like petrol station or rail station in accordance with PNEN 1991-1-4, but this type of mobile scene can also be with sheltered selected walls. That complicate classification of mobile scene to one type of building construction. To cover sides of mobile scene are commonly used with partially permeable, delicate material. The wind acting on the surface of this material will probably cause its deformation to some extent, but still in some part the air pressure will still affect the scene construction. In this case it's also necessary to take into account the influence of wind on the external surfaces of the mobile scene construction in the form of walls. However, this type of case is a very difficult issue to solve even with the help of a norms.

\section{Object research}

The model of analyzed hybrid multimedia mobile scene is shown in Fig. 1. The mobile scene construction consists of a truss base form with dimensions of $7695 \times 13174 \mathrm{~mm}$, which has been assigned a material in the form of steel S355J2H and a flat roof truss with dimensions of $10500 \times 15290 \mathrm{~mm}$. The height of the mobile scene from the ground is $8800 \mathrm{~mm}$. To the strength analysis was assigned to the roof material in the form of an aluminum alloy PA11 (Graczewski, 2019) characterized by very high fatigue strength and corrosion resistance.

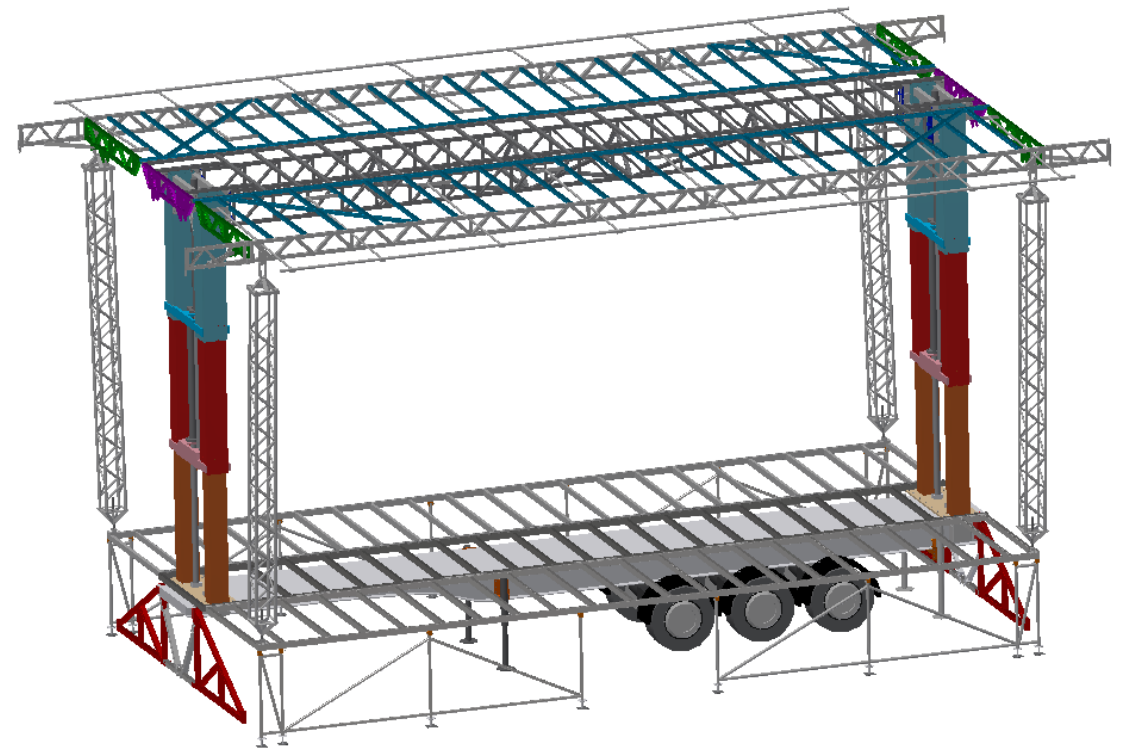

Fig. 1: Hybrid Multimedia Mobile Scene construction of steel and aluminum.

\section{Methods}

The strength analysis was carried out for two cases in which the main difference is the different location relative to which the values of the parameters presented in Tab. 1 of the norm used are adopted (PN-EN 1991-1-4, 2008). The presented model of hybrid multimedia mobile scene does not have fixed walls, which is why, according to PN-EN 1991-1-4, this type of object should be treated as a carport. One of the most important parameters in terms of wind influence on carports is the flow restriction factor $\varphi$. For the analyzed case, it was assumed that the surface area of the columns and elements of small architecture (stands, speakers, screens, lighting, etc.) placed on the stage together with people who may be under the shelter constitute $75 \%$ of the entire space, so the fill factor is $\varphi=075$. The roof slope of the analyzed construction 
is in the range of $-50<\alpha<50$, which according to the norm used is considered a flat roof. In relation to these arrangements, the wind direction and field distribution of three types of loads were adopted in accordance with the diagram presented in Fig. 2.

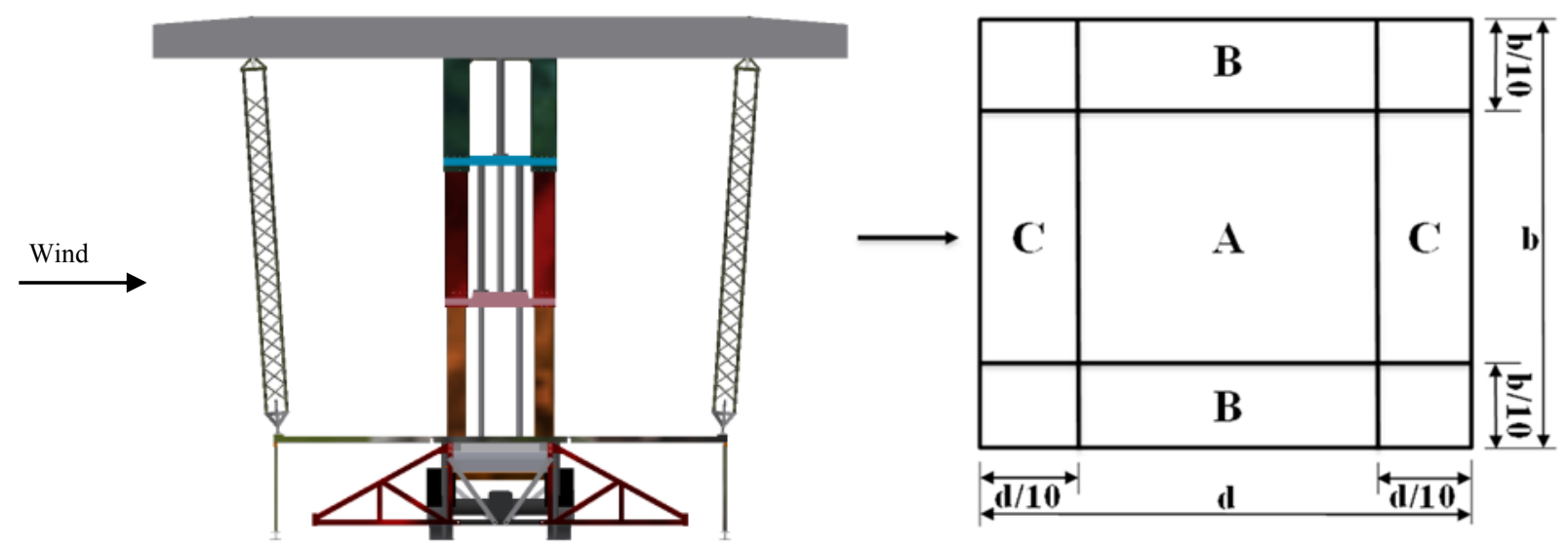

Fig. 2: Wind direction of the mobile scene construction together with the distribution of individual loads on the roof surface.

Tab. 1 shows the external wind pressure calculated in accordance with the applicable norm for two different locations.

Tab. 1: Value of external wind pressure [ $\left.\mathrm{kN} / \mathrm{m}^{2}\right]$ for two different locations.

\begin{tabular}{|c|c|c|}
\hline Area & Location 1 & Location 2 \\
\hline A & -0.558 & -0.998 \\
\hline B & -1.208 & -1.840 \\
\hline C & -1.301 & -3.318 \\
\hline
\end{tabular}

Location 1 is the place with the most difficult conditions taken into account of the wind influence in Poland. Location 2 refers to the place with the most difficult conditions taken into account of the wind influence in Switzerland. The analysis also took into account loads from suspended masses to the roof structure in the form of: LED screen (1.5 $\mathrm{t}$ ), four lighting lines ( $0.3 \mathrm{t}$ each) and four audio sets (1.2 $\mathrm{t}$ each).

\section{Results}

The results of the strength analysis of the wind effect on a flat roof of a hybrid multimedia mobile scene are shown in Fig. 3.

As a result of the strength analysis carried out at location 1 case, deformations were observed mainly from the suspended masses to the roof structure. The maximum value of this deformation is $16 \mathrm{~mm}$. Stress accumulation was also observed in the vicinity of the roof structure attachment to the columns of the base of the mobile scene. The value of these stresses does not exceed $30 \mathrm{MPa}$. The results of the analysis for location 2 represent a completely different form of deformation, which mainly comes from the wind load of the structure. The maximum deformation value in this case is $329 \mathrm{~mm}$. However, in this case there are many more places of stress accumulation exceeding places even $300 \mathrm{MPa}$.

\section{Conclusions}

The strength analysis of wind effect on the flat roof of the hybrid multimedia mobile scene construction has shown that the roof slope structure and the selected material is sufficient to meet even the most difficult conditions in Poland. It also indicates that adopted the same construction and material characteristics do not necessarily have to prove themselves in conditions in other countries. So producers of scenes referring to national norms of wind influence on mobile scenes can refer to constructions only if they are used in the country of the applicable norm. This is a kind of warning for mobile scene producers to pay attention to this problem when advertising their products. Otherwise, using a similar scene on the different location be were associated with a high risk of health and life threatening not only to the users of the scene, but also to its nearby environment. 

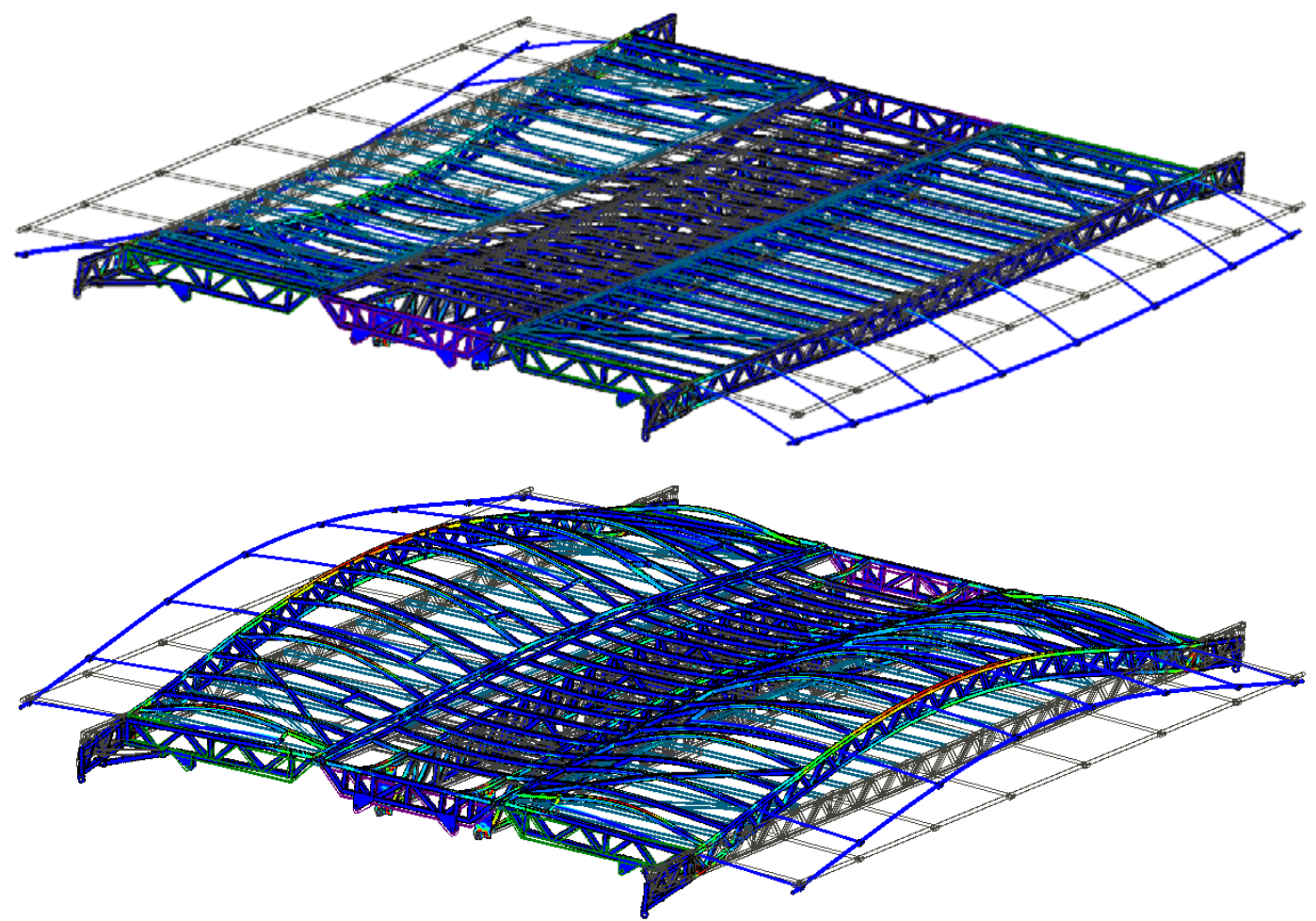

Fig. 3: Results of the strength analysis of the wind influence on a flat roof of a mobile scene construction (Top figure shows the results of Location 1 and the bottom figure shows results of Location 2).

\section{Acknowledgement}

This paper has been achieved under the research project "Hybrid multimedia mobile scenes are a chance for decisive innovation" No. POIR.04.01.04-00-0045/17-00.

\section{References}

Błyskal, E and Ślęczka, L. (2015) Spatial computational models of frame steel halls, Journal of Civil Engineering, Environment and Architecture, 62, pp. 25-36, (in Polish).

Graczewski, A., Ligaj, B. and Giętka, T. (2019) Influence of the Welding Method on the Strength of Structural Elements of Machines Made of Aluminum Alloy EN AW-5754. Scientific Session on Applied Mechanics X, Book Series: AIP Conference Proceedings, vol. 2077.

Kinasz, R. (2007) Analysis of the causes of the crash of the steel structure of the roof of an industrial hall, in: Proc. XXIII Konferencja Naukowo - Techniczna Zapobieganie, Diagnostyka, Naprawy i Rekonstrukcje, Szczecin, pp. 601-606, (in Polish).

Kozłowski, A. (2015) Steel structures. Wydawnictwo Politechniki Rzeszowskiej, Rzeszów, (in Polish).

Ligaj, B. and Sołtysiak, R. (2016) Problems of Equivalent Load Amplitude in Fatigue Life Calculations. Polish Maritime Research, 23, 1, pp. 85-92.

Lipecki, T. (2013) Wind impact on tall buildings in the light of own research and standard approaches, Budownictwo i Architektura, 12, 2, pp. 143-150, (in Polish).

Lipecki, T. (2015) Structure of wind and model tests of wind loads on cuboidal structures, Wydawnictwo Politechniki Lubelskiej, Lublin, (in Polish).

Łukasiewicz, M., Kałaczyński, T., Musiał, J. and Shalapko, J. (2014) Diagnostics of buggy vehicle transmission gearbox technical state based on modal vibrations. Journal of Vibroengineering, 16, 6, pp. 3137-3145.

PN-EN 1991-1-4:2008, Eurokod 1, Actions on structure, Part 1-4: General actions - Wind actions, (in Polish).

Strzelecki, P., Mazurkiewicz, A., Musiał, J., Tomaszewski, T. and Słomion, M. (2019) Fatigue Life for Different Stress Concetration Factors for Stainless Steel 1.4301. Materials, 12, pp. 1-9.

Supeł, $Ł$. and Jędrysiak, J. (2014) Analysis of the causes of failure of the steel lattice structure of the production hall, Architectura, 13, 3, pp. 39-49, (in Polish).

Żurański, J. and Gaczek, M. (2010) Wind load on buildings in terms of the standard PN-EN 1991-1-4:2008. Inżynieria i Budownictwo, 9, pp. 491-504, (in Polish). 